\title{
Well-being status and post-traumatic stress symptoms in health workers attending mindfulness sessions during the early stage of the COVID-19 epidemic in Mexico
}

\author{
Janet Real-Ramírez, ${ }^{1}$ Luis Alberto García-Bello, ${ }^{2}$ Rebeca Robles-García ${ }^{3}$ Montserrat Martínez, ${ }^{4}$ \\ Karime Adame-Rivas, ${ }^{4}$ Mariana Balderas-Pliego, ${ }^{4}$ Carolina García-Alfaro, ${ }^{4}$ Elisa Pérez-Cabañas, ${ }^{4}$ \\ Sandra Sierra-Medina, ${ }^{4}$ Mariajose Romero-González, ${ }^{5}$ Natasha Alcocer-Castillejos ${ }^{5}$
}

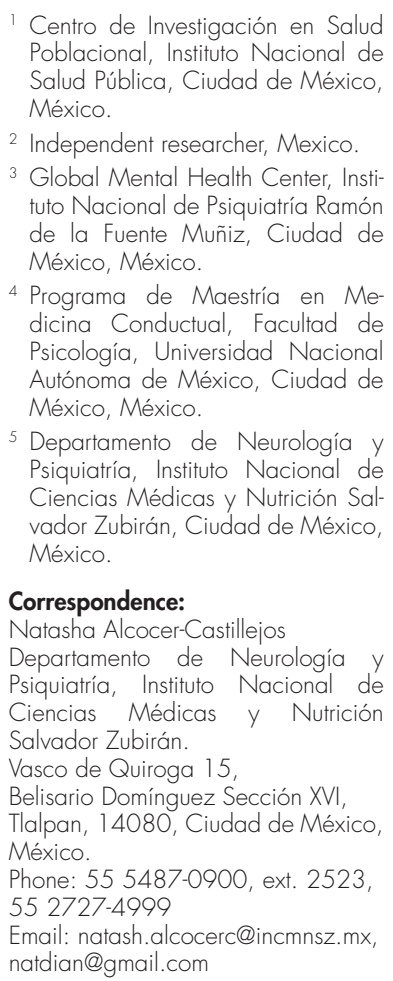

\section{Correspondence:}

Natasha Alcocer-Castillejos

Departamento de Neurología y Psiquiatría, Instituto Nacional de Ciencias Médicas y Nutrición Salvador Zubirán

Vasco de Quiroga 15,

Belisario Domínguez Sección XVI

Tlalpan, 14080, Ciudad de México, México.

Phone: 55 5487-0900, ext. 2523 55 2727-4999

Email: natash.alcocerc@incmnsz.mx, natdian@gmail.com

Received: 3 July 2020

Accepted: 18 August 2020

Citation:

Real-Ramírez, J., García-Bello, L. A. Robles-García, R., Martínez, M., Adame-Rivas, K., Balderas-Pliego, M. García-Alfaro, C., ... Alcocer-Castillejos, N. (2020). Well-being status and post-traumatic stress symptoms in health workers attending mindfulness sessions during the early stage of the COVID-19 epidemic in Mexico. Salud Mental, 43(6), 303-310.

DOI: 10.17711/SM.0185-3325.2020.041

\begin{abstract}
Introduction. In Mexico, a National Mental Health Strategy was implemented to identify and attend the mental health repercussions of the COVID-19 pandemic. It included the creation of five virtual clinics for health workers, being the Burnout, Post-traumatic Stress and Compassion Fatigue clinic one of them. Objective. To describe the basal sociodemographic and psychological characteristics of health workers attending online mindfulness sessions as part of the treatment of the aforementioned clinic. Method. This is a cross-sectional report part of a major nationwide and longitudinal project. All attendants responded to digital sociodemographics and COVID-19 questionnaires, the Extended Physician Well-Being Index (EPWBI), and the Post-traumatic Stress Disorder (PTSD) TOP-8 index. Results. Of the 507 health workers that participated, $70.02 \%$ of them were at risk of burnout according to the Extended Well-Being Index and $57.31,7.91$ and $2.77 \%$ had a mild, moderate, and severe risk of PTSD, respectively. The most affected were the female health workers, from metropolitan or central areas of the country, and those diagnosed with COVID-19 or exposed to a person with the diagnosis. Discussion and conclusion. Mexican health workers attending mindfulness sessions presented high frequencies of PTSD symptoms and burnout. Female workers at urban hospitals could be at a special risk for developing PTSD or Well-ness alterations, and thus, they must be cared for closely, particularly those having direct contact with COVID 19 positive persons. The early participation in mental health strategies might lessen the immediate and long-term pandemic effects.
\end{abstract}

Keywords: Well-being, burnout, post-traumatic stress disorder, mindfulness, COVID-19

\section{RESUMEN}

Introducción. En México se crearon cinco clínicas virtuales de salud mental para los trabajadores de la salud como parte de la respuesta nacional de salud mental ante la pandemia por COVID-19. La clínica de desgaste, estrés postraumático y fatiga por compasión es una de ellas. Objetivo. Describir las características sociodemográficas y psicológicas basales de los trabajadores de la salud que asistieron a las sesiones virtuales de atención plena, que constituyeron una de las estrategias de atención en la clínica. Método. Estudio transversal, parte de un proyecto nacional y longitudinal. Los participantes contestaron un cuestionario digital con preguntas sociodemográficas y sobre la situación actual del COVID-19, el Índice Extendido de Bienestar Médico y la escala TOP-8 de estrés postraumático. Resultados. De los 507 trabajadores de la salud que participaron, $70.02 \%$ presentaron riesgo de desgaste según el Índice de Bienestar Extendido, y 57.31, 7.91 y $2.77 \%$ de riesgo leve, moderado y grave en el TOP-8, respectivamente. Las mujeres, los habitantes de la zona metropolitana o del centro del país, aquellos con diagnóstico de COVID-19 y los expuestos a personas con dicho diagnóstico fueron los más afectados. Discusión y conclusión. Los participantes de las sesiones de atención plena presentaron altas frecuencias de síntomas de estrés postraumático y desgaste (burnout). Como las trabajadoras de zonas urbanizadas podrían correr un riesgo especial, debería dárseles un seguimiento especial, en particular a aquellas en contacto directo con personas positivas al COVID-19. La participación temprana en estrategias de salud mental podría amortiguar los efectos inmediatos y de largo plazo de la pandemia.

Palabras clave: Bienestar, desgaste profesional, trastorno por estrés postraumático, atención plena, COVID-19. 


\section{INTRODUCTION}

On March 11th 2020, the World Health Organization (WHO) made the assessment that COVID-19 could be characterized as a pandemic (World Health Organization, 2020a). The mexican government initiated the Healthy Distancing Journey on March 23th as a means to lessen the pandemic impact (López-Gatell Ramírez, 2020; Secretaría de Salud, 2020c). On April 10th, 18 days after this declaration, the National Mental Health Strategy for COVID-19 started official activities (Secretaría de Salud, 2020a).

Mental health impact by the pandemic on health workers had already been described in China, where high rates of depressive $(50.4 \%)$ and anxiety $(44.6 \%)$ symptoms, and insomnia (34\%) and distress (71.5\%) had been reported (Lai et al., 2020). In European countries, like Spain, a great proportion of health workers got infected with SARS-CoV-2 and this was related with elevated levels of depression, anxiety, and stress, although these were not statistically different from those of the general population (García-Fernández et al., 2020). With the aim of identifying and attending mental health symptoms among Mexican population during the pandemic, the Ministry of Health encouraged a national mental health strategy for COVID-19; health workers represent one specific target population. In order to have a therapeutic option for attending these workers, five virtual multisite clinics were formed to cover the most expected mental symptoms: 1 . Emotional crisis and suicide risk clinic (which offers 24/7 services and the possibility of hospitalization), 2. Substance abuse clinic, 3. Anxiety, depression and somatization clinic, 4. Mourning clinic, and 5. Burnout, post-traumatic stress disorder (PTSD), and compassion fatigue clinic (BPSCFc).

One of the treatment strategies of the BPSCFc was the generation of daily online mindfulness sessions in two different evening schedules. The present report has the main objective of describing the basal sociodemographic, COVID-19 related status and psychological (characteristics specifically the well-being and post-traumatic stress status) of the health workers who attended these sessions. We consider that the information obtained during the first seven weeks of the pandemic in our country may be useful for having an initial notion of the pandemic's early impacts on the mental health of health workers and the consideration of further strategies.

\section{METHOD}

\section{Study design}

This study is part of a major project named Evaluation of mental health, prevention and remote psychological strategies for health workers which is a nationwide longitudinal survey that aims to evaluate the presentation of mental health symptoms among health workers during the pandemic and to measure the effect of different clinical interventions (in press). Here, we present the basal evaluation of health workers attending the mindfulness sessions of our clinic from April 20th through June 4th, 2020.

\section{Procedure}

All health workers who had the possibility of connecting to the digital platform, laboring at public or private hospitals, whether it was a COVID-19 center or not, were eligible to attend the sessions. Participants of this sessions were recruited by one of two ways: 1 . the National Digital Survey of Mental Health made by the Universidad Nacional Autónoma de México (UNAM) and the Ministry of Health (UNAM \& Secretaría de Salud, 2020), available on the federal website coronavirus.gob.mx/salud-mental/, which detected and referred those health workers with burnout, post-traumatic stress symptoms, and/or compassion fatigue to our clinic (and other mental problems to their respective clinics). This was constructed with brief screening measures with proven adequate psychometric properties and applied through a WebApp as a single questionnaire (Cuestionario para la detección de riesgos a la salud mental COVID-19) that could be accessed by different systems (including Android $^{\circledR}$, iOS $^{\circledR}$, Symbian $^{\circledR}$, Windows ${ }^{\circledR}$, and WebOS ${ }^{\circledR}$ ). It includes a pseudo algorithm for rating and interpreting the scales prioritizing reference to treatment of the most serious problems of each participant (with suicide risk being the first to be addressed, followed by burnout, post-traumatic stress disorder and compassion fatigue) and gives the virtual clinic coordinator's number for further contact. 2. Health workers directly attending online mindfulness groups (without answering de National Digital Survey of Mental Health) because they were informed or invited by other ways (the National Mental Health Strategy and mindfulness sessions were broadcasted through the official specialized site for COVID19 of the Secretaría de Salud - coronavirus.gob.mx - and social networks like YouTube, COVID19 Press conferences, and the Institute of Health for Welfare (INSABI) Webinars (Secretaría de Salud, 2020a; 2020b; 2020c) and shared by Facebook, physicians', nurses' and other health personnel's Twitter groups). The participants recruited by the UNAM screening instrument were initially contacted by the clinic coordinator to receive information about the different treatment options (mindfulness sessions, individual brief psychotherapy, group psychotherapy, psychiatric evaluation) and decided with which to begin.

\section{Measurements}

All participants responded to a self-applied digital questionnaire that included: a. general sociodemographic and COVID-19 related questions, b. the Extended Physician 
Well-being Index (EPWBI), a questionnaire with nine items which evaluates overall quality of life. This Index was created at Mayo's Clinic and has different versions for medical students, residents, physicians, and general workers (GWWBI). The physician extended version and the general workers' version included two questions about satisfaction of work-life integration and work meaning which makes them able to identify high well-being. For these two versions (which have the same questions), the cut off points were $\geq$ 3 for physicians and $\geq 2$ for the rest of the health team. Using the cut-off points, the instruments have been reported to identify not only physicians and workers at distress, but also those at risk for adverse consequences (i.e., 2 fold higher risk of reporting a recent medical error, 2 fold higher risk of suicidal ideation, and 5 fold higher risk of burnout in those physicians with EPWBI $\geq 3$, and 2.1 fold higher risk of suicidal ideation, 2.9 fold higher risk of burnout, and 2.3 fold higher risk of poor overall quality of life for workers with GWWBI $\geq 2$ ). We used the respective cut-off points according to the kind of participants in our study (Dyrbye, Satele, \& Shanafelt, 2016; Shanafelt et al., 2014a), and c. The TOP-8, a short PTSD inventory with eight questions that evaluates and categorizes into four groups the presence of symptoms according to DSM-5 diagnostic criteria: risk free ( $<5$ points), mild risk (5-17 points), moderate risk (1825 points), and severe risk with probability of comorbidities (26-36 points). TOP-8 has shown good correlation with other PTSD instruments (Pearson's correlation coefficient of .91 with Davidson Trauma Scale) a high inter-rater reliability (.96) and good properties for assessing treatment outcomes (Davidson et al., 1997; Davidson \& Colket, 1997).

Participants were asked to respond to the afore-mentioned digital questionnaire before the first day of assistance to the online mindfulness groups. After completing the survey, they received an email message containing a general diagnosis (or the lack of it) and information for getting further professional attention with our team or one of the other clinics if needed.

\section{Statistical analysis}

Descriptive statistics included frequencies $(n)$ and percentages for categorical variables and mean and standard deviation for continuous variables. For the bivariate analysis, differences between risk groups were evaluated with Chi square $\left(\mathrm{X}^{2}\right)$ tests. Statistical significance was considered for $p<.05$. All statistical analyses were carried out using Stata software version 13.0 and the geospatial analysis with Mapa Digital 6.3.0 powered by INEGI.

\section{Ethical considerations}

Both the principal study and the partial survey reported here were conducted according to the general principles stated in the Declaration of Helsinki and were approved by the Research Ethics Committee of the Ramón de la Fuente National Institute of Psychiatry, in Mexico City, Mexico (April 16, 2020; principal investigator/responsible: Dr. Rebeca Robles García). All participants were asked to read and digitally sign the informed consent form.

\section{RESULTS}

Five hundred and seven health workers were included over the first seven weeks' period of the strategy. Of them, 37 $(1.38 \%)$ were recruited through UNAM's National Digital Survey of Mental Health. The principal sociodemographic characteristics are shown in Table 1. In general, three hundred and eighty-one participants $75.15 \%$ were women. The average age of participants was 38 years old $(S D=11.6)$, with the largest number of participants $38.07 \%$ at the 30 's, followed by those at 40 's $(26.43 \%)$. About half of the participants were single (51.48\%) and just under $40 \%$ were married or in a formal relationship. Of the total number of professionals, $50 \%$ had a bachelor's degree and $40.8 \%$ had a postgraduate degree or specialty.

Medical personnel were the most frequent health workers $34.52 \%$ attending the strategy. Of them, $45.71 \%$ were general practitioners, $44 \%$ specialists, and only $10.29 \%$ medical residents. Nursing staff was the second most frequent group $(24.85 \%)$, followed by psychology staff $(23.67 \%)$. Regarding the workplace profile, almost two thirds $65.29 \%$ worked at a non-social security public hospital (NSSPH) (Secretaría de Salud [SS] and INSABI), $18.93 \%$ at the private sector and $14.79 \%$ at social security public hospital (SSPH). Of the former group, almost all participants (96\%) worked either at the Instituto Mexicano del Seguro Social (IMSS) or at the Instituto de Seguridad y Servicios Sociales de los Trabajadores del Estado (ISSSTE), and only $4.0 \%$ at the health services of Petróleos Mexicanos (PEMEX), the Secretaría de Defensa Nacional (SEDENA) or Secretaría de Marina (SEMAR).

Considering the place of residence, $57.6 \%$ of the participants lived in the central zone of the country and its metropolitan area. The state of Oaxaca had 83 participants, representing $16.4 \%$, followed by Mexico City with $15.8 \%$, the State of Mexico with $12.2 \%$, and Sonora and San Luis Potosí with $9.5 \%$ and $8.1 \%$, respectively. The remaining $38.1 \%$ was distributed among the remaining 27 states of Mexico (Figure 1).

Most participants denied having COVID-19 symptoms at the time of registration in the BPSCFc. Only $9.27 \%$ met criteria for suspicious cases of COVID-19, had suspicion of COVID-19 in a family member or a close contact or had been in contact with people diagnosed with COVID-19 during the last 14 days. Five health workers (1\%) reported a confirmed diagnosis of COVID-19. 
Table 1

Sociodemographic characteristics of PSDCF group participants according to Extended Physician Well-Being Index Status

\begin{tabular}{|c|c|c|c|c|c|}
\hline \multirow[b]{3}{*}{ Variable } & & \multicolumn{2}{|c|}{ Well-Being Index } & & \multirow[b]{3}{*}{$X^{2} ; p$ value } \\
\hline & & $\begin{array}{c}\text { No risk } \\
n(\%)\end{array}$ & $\begin{array}{c}\text { At risk } \\
n(\%)\end{array}$ & & \\
\hline & $n=507(\%)$ & $152(29.98)$ & $355(70.02)$ & & \\
\hline \multicolumn{6}{|l|}{ Sex } \\
\hline Male & $125(24.65)$ & 44 (28.95) & 81 (22.82) & & $2.53(.282)$ \\
\hline Female & 381 (75.15) & 108 (71.05) & 273 (76.9) & & \\
\hline $\mathrm{N} / \mathrm{A}$ & $1(.2)$ & $0(0)$ & $1(.28)$ & & \\
\hline \multicolumn{6}{|l|}{ Age (years) } \\
\hline 20-29 & $89(17.55)$ & $21(13.82)$ & 68 (19.15) & & $12.44(.029)$ \\
\hline $30-39$ & $193(38.07)$ & $50(32.89)$ & $143(40.28)$ & & \\
\hline $40-49$ & $134(26.43)$ & $41(26.97)$ & $93(26.2)$ & & \\
\hline $50-59$ & $63(12.43)$ & $26(17.11)$ & $37(10.42)$ & * & \\
\hline 60 or more & $20(3.94)$ & $10(6.58)$ & $10(2.82)$ & * & \\
\hline $\mathrm{N} / \mathrm{A}$ & $8(1.58)$ & $4(2.63)$ & $4(1.13)$ & & \\
\hline \multicolumn{6}{|l|}{ Marital status } \\
\hline Single & 261 (51.48) & $74(48.68)$ & $187(52.68)$ & & $1.65(.438)$ \\
\hline Married or Free union & $196(38.66)$ & $65(42.76)$ & 131 (36.9) & & \\
\hline Separated & $50(9.86)$ & $13(8.55)$ & $37(10.42)$ & & \\
\hline \multicolumn{6}{|l|}{ Education } \\
\hline Elementary or middle & $45(8.88)$ & $20(13.16)$ & $25(7.04)$ & * & $9.84(.043)$ \\
\hline Undergraduate & $253(49.9)$ & $82(53.95)$ & 171 (48.17) & & \\
\hline Specialty & 111 (21.89) & $29(19.08)$ & $82(23.1)$ & & \\
\hline Postgraduate & 96 (18.93) & $21(13.82)$ & $75(21.13)$ & * & \\
\hline $\mathrm{N} / \mathrm{A}$ & $2(.39)$ & $0(0)$ & $2(.56)$ & & \\
\hline \multicolumn{6}{|l|}{ Area of residence ${ }^{\star *}$} \\
\hline North & $103(20.32)$ & $34(22.37)$ & $69(19.44)$ & & $16.69(.002)$ \\
\hline Center & $150(29.59)$ & $40(26.32)$ & $110(30.99)$ & & \\
\hline South & $107(21.1)$ & $47(30.92)$ & $60(16.9)$ & * & \\
\hline Mexico City's & $142(28.01)$ & $30(19.74)$ & $112(31.55)$ & * & \\
\hline $\mathrm{N} / \mathrm{A}$ & $5(.99)$ & $1(.66)$ & $4(1.13)$ & & \\
\hline \multicolumn{6}{|l|}{ Workplace Profile } \\
\hline SS, SES, INSABI (NSSPH) & 331 (65.29) & 109 (71.71) & 222 (62.54) & & $4.23(.238)$ \\
\hline Social Security (SSPH) & 75 (14.79) & $17(11.18)$ & $58(16.34)$ & & \\
\hline Private & $96(18.93)$ & $25(16.45)$ & $71(20)$ & & \\
\hline N/A & $5(.99)$ & $1(.66)$ & $4(1.13)$ & & \\
\hline \multicolumn{6}{|l|}{ Professional profile } \\
\hline Physician*** & $175(34.52)$ & $51(33.55)$ & 124 (34.93) & & $5.48(.484)$ \\
\hline Nurse & $126(24.85)$ & $46(30.26)$ & $80(22.54)$ & & \\
\hline Psychologist & $120(23.67)$ & $35(23.03)$ & $85(23.94)$ & & \\
\hline Social worker & $37(7.3)$ & $10(6.58)$ & $27(7.61)$ & & \\
\hline Paramedics & $15(2.96)$ & $4(2.63)$ & $11(3.1)$ & & \\
\hline Laboratory worker & $8(1.58)$ & $1(.66)$ & $7(1.97)$ & & \\
\hline N/A & $26(5.13)$ & $5(3.29)$ & $21(5.92)$ & & \\
\hline \multicolumn{6}{|l|}{ Situation with COVID-19 } \\
\hline No symptoms & $449(88.56)$ & $141(92.76)$ & $308(86.76)$ & & $8.23(.221)$ \\
\hline With acute respiratory disease & $7(1.38)$ & $1(.66)$ & $6(1.69)$ & & \\
\hline Suspicion of COVID-19 & $6(1.18)$ & $0(0)$ & $6(1.69)$ & & \\
\hline Suspicion of COVID-19 from a family member or close relative & $7(1.38)$ & $3(1.97)$ & $4(1.13)$ & & \\
\hline With COVID-19 diagnosis & $5(.99)$ & $0(0)$ & $5(1.41)$ & & \\
\hline Contact with person who had COVID-19 in the last 14 days & $27(5.33)$ & $5(3.29)$ & $22(6.2)$ & & \\
\hline $\mathrm{N} / \mathrm{A}$ & $6(1.18)$ & $2(1.32)$ & $4(1.13)$ & & \\
\hline
\end{tabular}

Notes: *Groups showing statistical differences $(p<0.05) .{ }^{*}$ Considering the classification proposed by ENSANUT 2012. Northern states: Sonora, Sinaloa, Coahuila de Zaragoza, Nuevo León, Tamaulipas, Chihuahua, Baja California, Baja California Sur. Central states: San Luis Potosí, Guanajuato, Puebla, Jalisco, Michoacán, Querétaro, Colima, Durango, Morelos, Tlaxcala, Zacatecas, Hidalgo, Nayarit, Aguascalientes. Southern states: Oaxaca, Veracruz, Yucatán, Chiapas, Quintana Roo, Campeche, Guerrero, Tabasco. Metropolitan area: Mexico City and State of Mexico. Abbreviations: NSSPH Non-Social Security Public Hospitals: includes Health Ministry (SS), State Health Services (SES), and Wellness Institute Hospitals (INSABI); SSPH: Social Security Public Hospitals, includes IMSS, ISSSTE, PEMEX, SEDENA and SEMAR Health Services, N/A: unanswered. ***The physician cut-off for WBIE > 3 and for the rest health personnel was $>2$. 


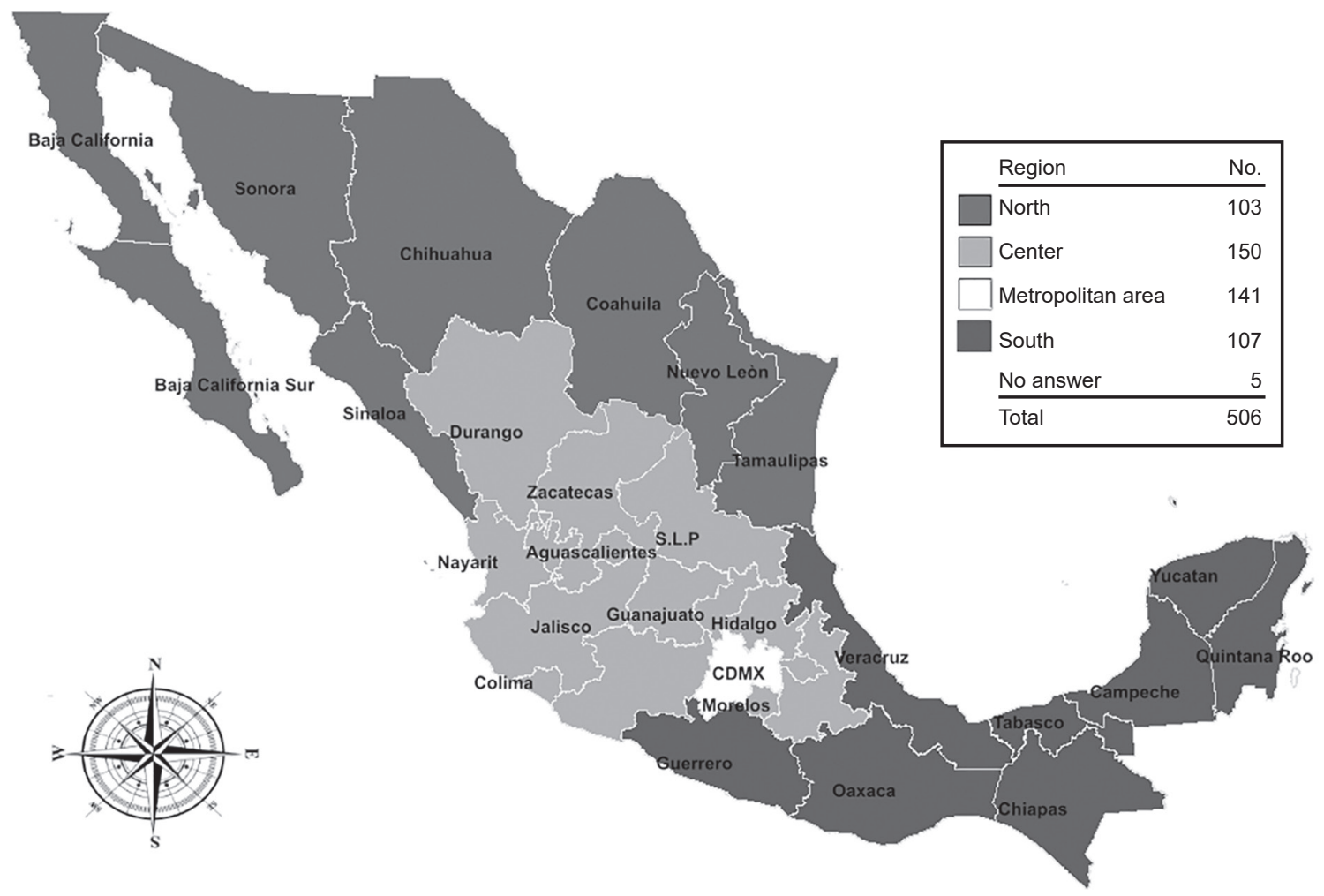

Figure 1. Regionalization of participants' response by residence area.

According to the EPWBI, $70.02 \%$ of the participants were at risk (cut-off $\geq 3$ points for physicians and $\geq 2$ for the rest of the health workers) at the basal evaluation. In the bivariate analysis, significant differences $(p<.05)$ in well-being status were observed among age groups, education level, and region of residence (Table 1). Medical staff presented the highest proportion of participants at risk $(34.93 \%$, ) while laboratory workers were the ones with the lower proportion (1.97\%) at risk. All participants with a confirmed COVID-19 diagnosis $(n=5)$ and 22 of the 27 participants $(81.48 \%)$ who had had contact with a COVID-19 positive person during the last 14 days scored with risk according to EPWBI.

On the other hand, according to the TOP- 8 score, answered by 506 participants, $57.31 \%$ had a mild risk of PTSD, $7.91 \%$ a moderate risk, and $2.77 \%$ a severe risk. A bivariate analysis of these categories with the socio-demographic variables showed significant differences $(p<.05)$ among the region of residence (higher frequency of mild, moderate, and severe risk for PTSD in the metropolitan zone of the country), the workplace profile (higher frequency of mild and moderate risk at NSSH and of severe risk at private institutions), and the professional profile (higher frequency of mild and moderate risk in physicians and nurses; higher free risk frequency in psychologist). Related to COVID-19 situation, of the 5 health workers with confirmed COVID-19 diagnosis, 3 (60\%) had mild PTSD risk and $1(20 \%)$ severe PTSD risk. Of the 27 participants who reported being in contact with a COVID-19 positive person during the last 14 days, 22 (81.48\%) had mild PTSD risk, and $3(11.11 \%)$ had severe PTSD risk (Table 2).

TOP-8 and EPWBI total scores were moderately and significantly correlated $(\mathrm{r}=.55, p<.01)$.

\section{DISCUSSION AND CONCLUSION}

The purpose of the present study was to explore sociodemographic and COVID-19-related characteristics of health workers assisting to mindfulness online sessions during the early phase (first seven weeks) of SARS-COV2 pandemic in Mexico, and to describe the prevalence of PTSD symptoms and alterations in well-being among the participants. Seventy percent of the health workers attending online group mindfulness sessions presented risk scores on the basal EPWBI. This is important to emphasize because, according to the Well-being Research Document (Dyrbye, Satele, Sloan, \& Shanafelt, 2013), scoring $\geq 3$ on EPWBI associated with a 2-fold higher risk of reporting a recent medical error, 5-fold higher risk of burnout, 4-fold higher risk of severe fatigue, 2-fold higher risk of suicidal ideation, and 3-fold higher risk of poor overall quality of life, all of which might impact in health workers well-being or even their families. In addition, there might be undesirable 
Table 2

Sociodemographic characteristics of BPSCFc participants and Post-Traumatic Stress Scale classification

\begin{tabular}{|c|c|c|c|c|c|c|}
\hline \multirow[b]{3}{*}{ Variable } & \multirow[b]{3}{*}{$N=506(\%)$} & \multicolumn{4}{|c|}{ TOP-8 Classification } & \\
\hline & & \multirow{2}{*}{$\begin{array}{c}\text { Risk free } \\
n(\%) \\
162(32.2)\end{array}$} & \multirow{2}{*}{$\begin{array}{c}\text { Mild } \\
n(\%) \\
290(57.31)\end{array}$} & \multirow{2}{*}{$\begin{array}{c}\text { Moderate } \\
n(\%) \\
40(7.91)\end{array}$} & \multirow{2}{*}{\multicolumn{2}{|c|}{$\begin{array}{c}\text { Severe } \\
n(\%) \\
14(2.77)\end{array}$}} \\
\hline & & & & & & \\
\hline \multicolumn{7}{|l|}{ Sex } \\
\hline Male & $125(24.70)$ & $44(27.16)$ & $66(22.76)$ & $9(22.5)$ & $6(42.86)$ & \\
\hline Female & $380(75.10)$ & $117(72.22)$ & $224(77.24)$ & $31(77.5)$ & $8(57.14)$ & \\
\hline $\mathrm{N} / \mathrm{A}$ & $1(.20)$ & $1(.62)$ & $0(.00)$ & $0(.00)$ & $0(.00)$ & \\
\hline \multicolumn{7}{|l|}{ Age (years) } \\
\hline $20-29$ & 89 (17.59) & $22(13.58)$ & 55 (18.97) & $9(22.50)$ & $3(21.43)$ & \\
\hline $30-39$ & $193(38.14)$ & $61(37.65)$ & $114(39.31)$ & $13(32.50)$ & $5(35.71)$ & \\
\hline $40-49$ & $134(26.48)$ & $41(25.31)$ & $78(26.90)$ & $12(30.00)$ & $3(21.43)$ & \\
\hline $50-59$ & $62(12.25)$ & $22(13.58)$ & $34(11.72)$ & $4(10.00)$ & $2(14.29)$ & \\
\hline 60 or more & $20(3.95)$ & $10(6.17)$ & $8(2.76)$ & $2(5.00)$ & $0(0)$ & \\
\hline $\mathrm{N} / \mathrm{A}$ & $8(1.58)$ & $6(3.70)$ & $1(.34)$ & $0(.00)$ & $1(7.14)$ & \\
\hline \multicolumn{7}{|l|}{ Marital status } \\
\hline Single & $261(51.58)$ & $86(53.09)$ & $143(49.31)$ & $27(67.50)$ & $5(35.71)$ & \\
\hline Married or Free union & $195(38.54)$ & $58(35.80)$ & $119(41.03)$ & $10(25)$ & $8(57.14)$ & \\
\hline Separated & $50(9.88)$ & $18(11.11)$ & $28(9.66)$ & $3(7.50)$ & $1(7.14)$ & \\
\hline \multicolumn{7}{|l|}{ Education } \\
\hline Elementary or middle & $45(8.89)$ & $14(8.64)$ & $22(7.59)$ & $6(15.00)$ & $3(21.43)$ & \\
\hline Undergraduate & $253(50.00)$ & $88(54.32)$ & $146(50.34)$ & $12(30.00)$ & $7(50.00)$ & \\
\hline Specialty & $111(21.94)$ & $28(17.28)$ & $65(22.41)$ & $15(37.50)$ & $3(21.43)$ & \\
\hline Postgraduate & 95 (18.77) & $32(19.75)$ & $55(18.97)$ & $7(17.50)$ & $1(7.14)$ & \\
\hline $\mathrm{N} / \mathrm{A}$ & $2(.40)$ & $0(.00)$ & $2(.69)$ & $0(.00)$ & $0(.00)$ & \\
\hline \multicolumn{7}{|l|}{ Area of residence ${ }^{* *}$} \\
\hline North & $103(20.36)$ & $46(28.40)$ & $50(17.24)$ & $6(15.00)$ & $1(7.14)$ & * \\
\hline Center & $150(29.64)$ & $46(28.40)$ & $85(29.31)$ & $13(32.50)$ & $6(42.86)$ & \\
\hline Sur & $107(21.15)$ & $35(21.60)$ & $68(23.45)$ & $3(7.50)$ & $1(7.14)$ & \\
\hline Metropolitan area & $141(27.87)$ & $33(20.37)$ & $85(29.31)$ & $17(42.50)$ & $6(42.86)$ & * \\
\hline $\mathrm{N} / \mathrm{A}$ & $5(.99)$ & $2(1.23)$ & $2(.69)$ & $1(2.50)$ & $0(.00)$ & \\
\hline \multicolumn{7}{|l|}{ Workplace Profile } \\
\hline NSSPH & $331(65.42)$ & $113(69.75)$ & $194(66.90)$ & $21(52.50)$ & $3(21.43)$ & * \\
\hline SSPH & 75 (14.82) & $18(11.11)$ & $46(15.86)$ & $7(17.50)$ & $4(28.57)$ & \\
\hline Private & $95(18.77)$ & $30(18.52)$ & $46(15.86)$ & $12(30.00)$ & $7(50.00)$ & * \\
\hline $\mathrm{N} / \mathrm{A}$ & $5(099)$ & $1(.62)$ & $4(1.38)$ & $0(.00)$ & $0(.00)$ & \\
\hline \multicolumn{7}{|l|}{ Professional profile } \\
\hline Physician & $175(34.58)$ & $48(29.63)$ & $105(36.21)$ & $19(47.50)$ & $3(21.43)$ & \\
\hline Nurse & $126(24.90)$ & $35(21.60)$ & $78(26.90)$ & $10(25.00)$ & $3(21.43)$ & \\
\hline Psychologist & $119(23.52)$ & $53(32.72)$ & $62(21.38)$ & $3(7.50)$ & $1(7.14)$ & * \\
\hline Social worker & $37(7.31)$ & $14(8.64)$ & $20(6.9)$ & $2(5.00)$ & $1(7.14)$ & \\
\hline Paramedics & $15(2.96)$ & $4(2.47)$ & $7(2.41)$ & $2(5.00)$ & $2(14.29)$ & \\
\hline Laboratory worker & $8(1.58)$ & $2(1.23)$ & $3(1.03)$ & $0(.00)$ & $3(21.43)$ & * \\
\hline $\mathrm{N} / \mathrm{A}$ & $26(5.14)$ & $6(3.7)$ & $15(5.17)$ & $4(10.00)$ & $1(7.14)$ & \\
\hline \multicolumn{7}{|l|}{ Situation with COVID-19 } \\
\hline No symptoms & $448(88.54)$ & $151(93.21)$ & $251(86.55)$ & $36(90.00)$ & $10(71.43)$ & \\
\hline With acute respiratory disease & $7(1.38)$ & $3(1.85)$ & $3(1.03)$ & $1(2.50)$ & $0(.00)$ & \\
\hline Suspicion of COVID-19 & $6(1.19)$ & $1(.62)$ & $3(1.03)$ & $2(5.00)$ & $0(.00)$ & \\
\hline Suspicion of COVID-19 from a family member or close relative & $7(1.38)$ & $1(.62)$ & $6(2.07)$ & $0(.00)$ & $0(.00)$ & \\
\hline With COVID-19 diagnosis & $5(.99)$ & $1(.62)$ & $3(1.03)$ & $0(.00)$ & $1(7.14)$ & \\
\hline Contact with person who had COVID-19 in the last 14 days & $27(5.34)$ & $2(1.23)$ & $22(7.59)$ & $0(.00)$ & $3(21.43)$ & * \\
\hline N/A & $6(1.19)$ & $3(1.85)$ & $2(.69)$ & $1(2.50)$ & $0(.00)$ & \\
\hline
\end{tabular}

Notes: *Groups showing statistical differences $(p<0.05) .{ }^{*}$ Considering the classification proposed by ENSANUT 2012. Northern states: Sonora, Sinaloa, Coahuila de Zaragoza, Nuevo León, Tamaulipas, Chihuahua, Baja California, Baja California Sur. Central states: San Luis Potosí, Guanajuato, Puebla, Jalisco, Michoacán, Querétaro, Colima, Durango, Morelos, Tlaxcala, Zacatecas, Hidalgo, Nayarit, Aguascalientes. Southern states: Oaxaca, Veracruz, Yucatán, Chiapas, Quintana Roo, Campeche, Guerrero, Tabasco. Metropolitan area: Mexico City and State of Mexico. Abbreviations: NSSPH: Non-Social Security Public Hospitals, SSPH: Social Security Public Hospitals, N/A: unanswered. 
effects for the patients' safety. High rates of burnout and mental health problems on physicians and nurses had already been reported worldwide before the pandemic and were being attended and monitored as they meant a great risk for patient care (Panagioti et al., 2018). Health workers well-being, then, should be monitored even more closely during and after this pandemic.

Risk, according to the EPWBI, was more frequent in female workers between 30 to 49 years old, for those living in metropolitan or central zones of the country (the regions more affected during the pandemic), for physicians (although not statistically significant), and for those being diagnosed with COVID-19 or exposed to a person with the diagnosis during the last 14 days. Likewise, $68 \%$ of the participants had mild to high risk of PTSD according to TOP8 (although only $10.6 \%$ had moderate or high scores), and the risk was higher for those living at Mexico City and its metropolitan area, working at private institutions, being female, a physician or a nurse, and having been diagnosed with COVID-19 or exposed to a person with the diagnosis during the last 14 days. The latter is consistent with other studies that have found higher vulnerability for PTSD in urban women due to biological factors, a higher occurrence of previous traumatic events, and more difficult social conditions (Robles-García, Fresán, \& Yoldi, 2020), all of which continue to be risk factors at our country, adding now the great fear, especially in female health workers, of getting infected by SARS-COV2 and transmitting it to their families. Thus, female health workers at urban hospitals could be at special risk for developing PTSD and must be followed up and supported during the actual pandemic. We consider that one aspect of the interventions must be directed to comfort and guarantee safety and early attention for their families in case they get COVID-19. Our virtual clinic offers support for the health workers giving feedback and offering other psychological therapeutic alternatives when the screening tests score with risk.

The PTSD frequencies here reported are higher than those reported for general population (10\%) (White et al., 2015 ) for health workers (33\%) (Luftman et al., 2017) or even emergency physicians (15.8\%) (DeLucia et al., 2019) before COVID-19 pandemic, although different measuring instruments were used and our prevalence includes mild cases of PTSD and, so, results cannot be totally comparable. Anyway, even mild cases detection offers the opportunity for early intervention, so we found it useful to report the data. Well-being risk (considering well-being as an opposite to burnout) coincides with the prevalence reported on other health workers (i.e., 24\%) in the U.S.A. Surgeons (Shanafelt et al., 2014a), 34\% in oncologists (Shanafelt et al., 2014b), and the general prevalence of burnout syndrome before the pandemic (44\%) (Kane, 2019).

Although some of the participants were recruited through the UNAM's National Digital Survey of Mental
Health (1.38\%), most assisted by direct invitation of other health workers or thanks to the broadcasting of the strategy. This is positive because we can say that the target population has been reached in a friendly way and this can be a good strategy for reducing the mental assistance gap (World Health Organization, 2020c). Additionally, most of the participants were not pre-selected for having burnout, post-traumatic stress or compassion fatigue symptoms, and may be considered more representative of general population of health workers who can then be assumed to have had high levels of distress at the early phase of the pandemic.

Something else to be considered, in the particular case of Mexico, is that the community spread phase of COVID-19 conditioned many changes at the sanitary organization: massive hiring of health personnel (Secretaría de Salud, 2020c) and the increase of new COVID cases (among others) all of which had a great impact the on the resilience ability of the health personnel (United Nations, 2020). The aforementioned reinforces the importance of detecting and attending health workers' mental health, especially at crises times as the actual pandemic.

Limitations: As this is a cross-sectional view of a group attending an intervention, no causal inferences can be made. Furthermore, we did not analyze the existence of other psychiatric comorbidities, although many of the participants were initially filtered through the National Survey, which gives the opportunity to analyze this on the future. The representativeness of the sample might have been biased due to the limitations of the access to the internet signal in many rural areas of the country and the scope of the information disseminated and broadcasted throughout the social media. Also, even when INEGI reports that $44.6 \%$ of the Mexican population has internet access, non-medical staff may have more barriers for internet access, less resources for having computers or smartphones, or digital gaps that may hamper their participation, and thus might have been underrepresented. We did not explore the percentage of participants that were front-line health workers nor if they were staff physicians or medical residents. More specific studies with these particular workers would be important.

In conclusion, the present study shows that healthcare workers are at risk of suffering mental health symptoms and of developing PTSD. Seven weeks after initiating the National Mental Health Evaluation, Prevention and Remote psychological strategies for health workers, we observed the health workers' participation throughout many regions of the country. In addition to being a challenge, it also represents an opportunity to generate digital programs and integrated networks in order to provide mental health the kind of care that promotes a better quality of life, just like the WHO has recommended (Organización Mundial de la Salud, 2013; World Health Organization, 2020b).

We believe that these results highlight the feasibility of screening and initially attending all health workers re- 
motely as a prevention strategy for mental health which can be extended to all health dependences as a national mental health observatory for the mental health consequences of COVID-19 pandemic that has just started.

\section{Funding}

None.

\section{Conflicts of interest}

The authors declare they have no conflicts of interest.

\section{Acknowledgements}

We thank Dr. Thierry Hernández Gilsoul for reviewing the final version of the article, and Janet Jazmin Montes Trejo for borrowing online sessions license.

\section{REFERENCES}

Davidson, J. R. T., \& Colket, J. T. (1997). The eight-item treatment-outcome posttraumatic stress disorder scale: A brief measure to assess treatment outcome in post-traumatic stress disorder. International Clinical Psychopharmacology, 12(1), 41-45. doi: 10.1097/00004850-199701000-00006

Davidson, J. R. T., Book, S. W., Colket, J. T., Tupler, L. A., Roth, S., David, D., ... Feldman, M. E. (1997). Assessment of a new self-rating scale for post-traumatic stress disorder. Psychological Medicine, 27(1), 153-160. doi: 10.1017/ S0033291796004229

DeLucia, J. A., Bitter, C., Fitzgerald, J., Greenberg, M., Dalwari, P., \& Buchanan, P. (2019). Prevalence of post-traumatic stress disorder in emergency physicians in the United States. Western Journal of Emergency Medicine, 20(5), 740-746. doi: 10.5811/westjem.2019.7.42671

Dyrbye, L. N., Satele, D., \& Shanafelt, T. D. (2016). Ability of a 9-Item Well-Being Index to Identify Distress and Stratify Quality of Life in US Workers. Journal of Occupational and Environmental Medicine, 58(8), 810-817. doi: 10.1097/ JOM.0000000000000798

Dyrbye, L. N., Satele, D., Sloan, J., \& Shanafelt, T. D. (2013). Utility of a brief screening tool to identify physicians in distress. Journal of General Internal Medicine, 28(3), 421-427. doi: 10.1007/s11606-012-2252-9

García-Fernández, L., Romero-Ferreiro, V., López-Roldán, P. D., Padilla, S., CaleroSierra, I., Monzó-Garci, M., ... Rodriguez-Jimenez, R. (2020). Mental health impact of COVID-19 pandemic on Spanish healthcare workers. Psychological Medicine, 3, 17-19. doi: 10.1017/S0033291720002019

Kane, L. (2019). Medscape National Physician Burnout, Depression \& Suicide Report 2019, (pp. 1-29). New York, NY: Medscape.

Lai, J., Ma, S., Wang, Y., Cai, Z., Hu, J., Wei, N., ... Hu, S. (2020). Factors associated with mental health outcomes among health care workers exposed to coronavirus disease 2019. JAMA Network Open, 3(3), e203976. doi: 10.1001/ jamanetworkopen.2020.3976

Luftman, K., Aydelotte, J., Rix, K., Ali, S., Houck, K., Coopwood, T. B., ... Davis, M. (2017). PTSD in those who care for the injured. Injury, 48(2), 293-296. doi: 10.1016/j.injury.2016.11.001
López-Gatell Ramírez, H. (2020). Mañana 23 de marzo inicia la Jornada Nacional de Sana Distancia. Twitter. Retrieved from https://twitter.com/HLGatell/ status/1241918043128815617

Organización Mundial de la Salud. (2013). Plan de Acción Sobre Salud Mental 2013 2020. Organización Mundial de La Salud, (pp. 54). Retrieved from https://www. who.int/mental_health/publications/action_plan/es/

Panagioti, M., Geraghty, K., Johnson, J., Zhou, A., Panagopoulou, E., Chew-Graham, C., ... Esmail, A. (2018). Association between Physician burnout and patient safety, professionalism, and patient satisfaction: A systematic review and meta-analysis. JAMA Internal Medicine, 178(10), 1317-1331. doi: 10.1001/ jamainternmed.2018.3713

Robles-García, R., Fresán, A., \& Yoldi, M. (2020). Posttraumatic stress disorder in urban women. Current Opinion in Psychiatry, 33(3), 245-249. doi: 10.1097/ YCO.0000000000000585

Secretaría de Salud. (2020a). \#ConferenciaDePrensa: \#COVID19 \#QuédateEnCasa 10 de abril de 2020. In Presentación de la Estrategia Nacional en Salud Mental. YouTube. https://www.youtube.com/watch?v=zr6_Ji0yqec\&list=PL-wEE8Vm WaJ1XfDoFFkVfxuwVRgBMIiNO\&index $=5 \mathrm{E}$

Secretaría de Salud. (2020b). Conferencia de Prensa \#COVID19 \#QuédateEnCasa | 9 de mayo de 2020 \#GraciasPorCuidarnos. In Presentación de la Estrategia Nacional en Salud Mental Trabajadores de la salud. YouTube. https://www. youtube.com/watch? $\mathrm{v}=\mathrm{O}$-sCtAXBtrA\&feature=youtu.be

Secretaría de Salud. (2020c). Declaratoria de Fase 2 por coronavirus COVID-19| 24 de marzo 2020. Coronavirus.Gob.Mx. Retrieved from https://coronavirus.gob. $\mathrm{mx} / 2020 / 03 / 24 /$ inicia-fase-2-por-coronavirus-covid-19/

Shanafelt, T. D., Kaups, K. L., Nelson, H., Satele, D. V., Sloan, J. A., Oreskovich, M. R., \& Dyrbye, L. N. (2014a). An interactive individualized intervention to promote behavioral change to increase personal well-being in US surgeons. Annals of Surgery, 259(1), 82-88. doi: 10.1097/SLA.0b013e3182a58fa4

Shanafelt, T. D., Raymond, M., Horn, L., Moynihan, T., Collichio, F., Chew, H., ... Gradishar, W. J. (2014b). Oncology fellows' career plans, expectations, and well-being: Do fellows know what they are getting into? Journal of Clinical Oncology, 32(27), 2991-2997. doi: 10.1200/JCO.2014.56.2827

UNAM., \& Secretaría de Salud. (2020). Instrumento para la detección de riesgos a la salud mental COVID-19. Retrieved from https://misalud.unam.mx/covid19/

United Nations. (2020). Policy Brief: COVID-19 and the Need for Action on Mental Health. Retrieved from https://unsdg.un.org/sites/default/files/2020-05/UNPolicy-Brief-COVID-19-and-mental-health.pdf

White, J., Pearce, J., Morrison, S., Dunstan, F., Bisson, J. I., \& Fone, D. L. (2015). Risk of post-traumatic stress disorder following traumatic events in a community sample. Epidemiology and Psychiatric Sciences, 24(3), 249-257. doi: 10.1017/ S2045796014000110

World Health Organization. (2020a). Archived: WHO Timeline - COVID-19. Retrieved from https://www.who.int/news-room/detail/27-04-2020-who-timeline---covid-19

World Health Organization. (2020b). Draft global strategy on digital health 2020-2025. WHO. Retrieved from https://www.who.int/docs/default-source/ documents/gs4dhdaa2a9f352b0445bafbc79ca799dce4d.pdf

World Health Organization. (2020c). Mental Health and Psychosocial Considerations During COVID-19 Outbreak - January, (pp. 1-6). WHO. 